\title{
28 Research Square \\ Hsp90 inhibitors directly block HSV-1 DNA replication via inducing degradation of pUL42
}

\section{Shurong Qin}

Jinan University

Xiao Hu

Jinan University

Qiongzhen Zeng

Jinan University

Zhaoyang Wang

Jinan University

jiaoyan Jia

Jinan University

Xiaowei Song

Jinan University

zhe Ren

Jinan University

Yifei Wang ( $\nabla$ twang-yf@163.com )

Jinan University https://orcid.org/0000-0002-9918-2865

\section{Research Article}

Keywords: HSV-1, AT-533, 17-AAG, DNA replication, protein docking, pUL42

Posted Date: March 10th, 2021

DOI: https://doi.org/10.21203/rs.3.rs-261344/v1

License: (c) (i) This work is licensed under a Creative Commons Attribution 4.0 International License.

Read Full License 


\section{Abstract}

Background囚Herpes simplex virus type I (HSV-1) is a member of the Alphaherpesvirinae family, which could initiate labial herpes caused by the reactivation of HSV-1 primary infection, and genital herpes caused by secondary infection, even causes herpes encephalitis. The purpose of this study is to study potential viral proteins and the mechanism of antiviral activity of new Hsp90 inhibitors (AT-533 and 17$A A G)$. In previous studies, the Hsp90 inhibitor geldanamycin has been confirmed to induce the abnormal localization of HSV-1 pUL30, but it is unclear whether Hsp90 inhibitors affect other viral replication proteins.

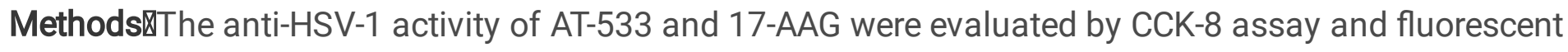
virus titer assay. The mechanism of action against HSV-1 DNA replication was determined by the previous study and this research. Then we assayed the viral RNA transcription, viral DNA replication and protein expression, respectively. In addition, we identified the replication-related proteins that interact with Hsp90 through protein docking and co-immunoprecipitation, and determined the effects of AT-533 and 17-AAG on the expression of replication-related proteins.

Results囚CCK-8 and fluorescent virus titer determination showed that Hsp90 inhibitors hasve good antiHSV-1 activity on HFF cells. Interestingly, AT-533 significantly reduces the synthesis of viral DNA, but it does not affect the expression of viral mRNA. Further, protein docking stimulation and co-IP assay revealed that DNA polymerase pUL42 interacted with Hsp90, which was largely degraded via autophagy by Hsp90 inhibitors. However, AT-533 does not affect the expression of other replication-related proteins, such as ssDNA binding protein UL9 and helicase-primerase UL5/8/52. The results suggested that Hsp90 inhibitors directly inhibited viral DNA replication by affecting the stability of DNA polymerase pUL42.

Conclusions $囚 \mathrm{Our}$ results indicate that Hsp90 inhibitors may be potential candidates for HSV-1 therapy by directly inhibiting DNA replication, especially for ACV resistant strains.

\section{Introduction}

Herpes simplex virus-1 (HSV-1), a common human pathogenic viruse, belongs to a herpesvirinae family[1]. HSV-1 could initiate labial herpes caused by the reactivation of HSV-1 primary infection, and genital herpes caused by secondary infection even causes herpes encephalitis[2]. Specifically, HSV-1 contains at least 7 conserved protein to effect DNA replication, such as origin-binding protein UL9, singlestranded DNA binding protein ICP8, DNA polymerase complex UL30/42 and helicase-primase complex UL5/8/52[3]. Among the most important HSV-1 proteins, HSV-1 DNA polymerase and the early enzyme thymidine kinase (TK) play a key role in the virus replication process, so drugs targeting these proteins

may disrupt the virus replication cycle ${ }^{[4]}$. At present, nucleic acid analogs have been used as anti-HSV-1 drugs in the clinical frontline, which target the stage of viral DNA replication, especially acting on thymidine kinase (TK). The representative drug is acyclovir and its derivatives. Due to the limitations of 
nucleoside analog drugs, patients who take these drugs for a long time to treat HSV-1 infection may induce drug-resistant virus strains and adverse reactions[5].

Recently, many studies have indicated that heat shock protein 90 (Hsp90) is a promising broad-spectrum antiviral host factor, which is required by many viruses for multiple phases of their life cycle including viral entry, nuclear import, transcription, and replication[6]. Previous research indicated that Hsp90 inhibitor geldanamycin reduced viral titers and induced the abnormal location of HSV-1 DNA polymerase catalytic subunit $\mathrm{pU}_{\mathrm{L}} 30[7]$. However, the particular interaction between Hsp90 and HSV-1 replicationrelated proteins still unknown. In this study, we further studied the potency and mechanism of antiviral activity of novel Hsp90 inhibitor AT-533 against HSV-1 DNA replication-related proteins and ACV-resistant strains.

\section{Materials And Methods}

\section{Inhibitors, antibodies and plasmids}

AT-533 was systematically synthesized in a previously reported study [8], and 17-N-allylamino 17demethoxygeldanamycin (17-AAG) (S1141) was purchased from Selleck. Cell Counting Kit-8(CCK-8)was obtained from Beyotime Biotechnology. Trizol Reagent was purchased from Invitrogen (Carlsbad, CA, USA). Dulbecco's modified Eagle medium (DMEM), fetal bovine serum (FBS), and penicillin-streptomycin were bought from Gibco-BRL (Gland Island, NY, USA). Ubiquitin - proteasome inhibitor MG-132 was purchased from Selleck (S2619), and autophagy inhibitor chloroquine (CQ) was purchased from SigmaAldrich (C6628). These compounds were dissolved into designated concentration in dimethylsulfoxide (DMSO), whose final concentrations were less than $0.1 \%$. The primary antibodies used in this study included mouse monoclonal antibodies (MAb) against HSV-1 ICP8 (Santa Cruz,11E2), HSV-1 pUL42 (Abcam, ab19311), LC3B (Cell Siganling technology, 2775) and rabbit monoclonal antibodies (Mab) against Total Hsp90 (Abcam,ab13492), Ubiquitin-P4D1 (Cell Siganling technology, 3936), Akt (Cell Siganling technology, 13038S), GAPDH (GeneTex, GTX100118), Flag-tag (Cell Siganling technology, 14793S), HA-tag (Cell Siganling technology, 3724), GFP-tag (Beyotime Biotechnology, AF0159). The secondary antibodies mainly included anti-rabbit IgG light chain(Abbkine, A25022) and anti-mouse IgG light chain(Abbkine, A25012). All the eukaryotic expression plasmids, including pLVX-EGFP-C1-UL30, pCMV-HA-UL42, p3xFLAG-UL5, pCMV-HA-UL8, pLVX-EGFP-UL52 were generated in our laboratory. cDNA was reverse transcripted using RNA obtained from HSV-1-infected cells as a template to amplify the virus coding sequence. All constructed plasmids were verified by DNA sequencing (TSINGKE Biological Technology). For information on the primers and vectors used to construct the plasmids, see Additional file 1: Table S1.

\section{Cells and viruses}

Human foreskin fibroblast(HFF, ATCC SCRC1041), Human embryonic kidney cells (HEK293T,ATCC CRL1573), African green monkey kidney cells (Vero, ATCC CCL181) were cultured in Dulbecco's modified Eagle's medium (DMEM, Gibco) complemented with 10\% fetal bovine serum (FBS, Gibco). The 
maintenance medium used for the dilutions of virus and reagents was DMEM complemented with $2 \%$ FBS. HSV-1/F (ATCC VR-733) was obtained from Hong Kong University. ACV-resistant clinical HSV-1 strain (HSV-1/153), a TK-mutant derived from HSV-1 (KOS)-HSV-1/Blue[8] were a kind present from Tao Peng (Guangzhou Institutes of Biomedicine and Health, Chinese Academy of Sciences). These above viruses were propagated in Vero cells and preserved at $-80^{\circ} \mathrm{C}$ until use.

\section{CCK-8 assay}

The CCK-8 assay was manipulated according to the suppliers protocol (Beyotime Biotechnology, C0037). Briefly, HFF cells were cultured in 96 -wells plates and reached at $85 \%$ cell confluence. Various concentrations of compound were added to the plate, with each concentration having three replicates. After $48 \mathrm{~h}$ of incubation, $10 \mu \mathrm{L}$ CCK-8 solution $(5 \mathrm{mg} / \mathrm{mL})$ was added to each well, and the plate was incubated for $1 \mathrm{~h}$ protected form light. Then, the plates incubated for $10 \mathrm{~min}$ at room temperature with gently shaking. The optical density (OD) at $450 \mathrm{~nm}$ was measured for each well with an enzyme-labeled reader (Bio-Rad, Hercules, CA, USA). The $50 \%$ cytotoxicity concentration $\left(\mathrm{CC}_{50}\right)$ was defined as the concentration to reduce $50 \%$ cell viability.

\section{Viral titer determination}

Vero cells were cultured in 96-wells plates. And the next day, Vero cell monolayers were incubated with eleven-fold serial dilutions of $100 \mu \mathrm{HSV}-1$ treatment and incubated at $37^{\circ} \mathrm{C}$ and $5 \% \mathrm{CO} 2$ for $72 \mathrm{~h}$. Morphological changes of the cells (cytotoxic effects, CPEs) were observed every day under inverted microscope and cell viability was calculated based on CPEs. Control were cells treated only with maintenance medium DMEM. The plaque assay was carried out in triplicate. Virus was quantified by serial dilution and titration assay. The $\operatorname{TCID}_{50}(50 \%$ tissue culture infectious dose) was calculated using the formula of Reed and Muench method

$\log _{10} 50 \%$ end point dilutions $=\log _{10}$ of dilution showing a mortality next above $50 \%$ - (difference of logarithms $\times$ logarithm of dilution factor). Difference of logarithms $=[($ mortality at dilution next above $50 \%)-50 \%] /[($ mortality next above $50 \%$ ) - (mortality next below $50 \%)][9]$.

\section{Antiviral effect of GFP-HSV-1}

HFF cells were cultured in 96-wells plates, and the second day cell monolayers were incubated with eleven-fold serial dilutions of $100 \mu \mathrm{Hsp} 90$ inhibitor treatment and infected $\mathrm{MOI}=1 \mathrm{GFP}-\mathrm{HSV}-1$ at $37^{\circ} \mathrm{C}$ and $5 \% \mathrm{CO} 2$ for $72 \mathrm{~h}[10]$. The plaque assay was carried out in triplicate. GFP fluorescence was quantified using a Synergy Neo HTS Multi-Mode Reader (Biotek Instruments). The relative fluorescence intensity was calculated using the formula as follows: Relative fluorescence intensity $=(\mathrm{Hsp} 90$ inhibitors treatment fluorescence intensity) / (GFP-HSV-1 control fluorescence intensity) $\times 100 \%$.

\section{CPEs Cell viability assay}

HFF cells were cultures in 96-well plates. And the next day, HFF cell monolayers were incubated with eleven-fold serial dilutions of $100 \mu \mathrm{L} \mathrm{HSV}-1$ treated with or without $\mathrm{Hsp} 90$ inhibitors at $37^{\circ} \mathrm{C}$ and $5 \% \mathrm{CO}_{2}$. 
After $72 \mathrm{~h}, 10 \mu \mathrm{L}$ CCK-8 solution was added to each well, and incubated for $1 \mathrm{~h}$ in dark. Then, the plates incubated for $10 \mathrm{~min}$ at room temperature with gently shaking. The optical density (OD) at $450 \mathrm{~nm}$ was measured for each well with an enzyme-labeled reader (Bio-Rad, Hercules, CA, USA). The CPEs inhibition ratio was calculated by the formula as follows. The CPEs inhibition ratio= [(Absorption of treatment groups) - (Absorption of cell control)] / [(Absorption of virus control) - (Absorption of cell control)] $\times 100 \%$ [11].

\section{The detection of DNA synthesis}

HFF cells were cultured in 12-well plates. And the second day cells infected with HSV-1 $(\mathrm{MOI}=20)$ were incubated with or without AT-533 or 17-AAG for $12 \mathrm{~h}$. Viral DNA was extracted using GeneJET Viral DNA and RNA Purification Kit (Thermo). Real-time PCR assay was used to quantify the viral DNA. Then the HSV-1 DNA copy numbers were expressed relative to the virus control groups. The primer pairs are seen at Additional file 1: Table S2.

\section{Real-time PCR (Q-PCR)}

HFF cells were cultured in 12-well plates. And the second day cells infected with HSV-1 $(\mathrm{MOI}=20)$ were incubated with or without AT-533 or 17-AAG for 2, 3, 4 h, respectively. Total RNA was isolated using Trizol (Invitrogen) and subjected to cDNA synthesis using a PrimeScript RT reagent kit (Takara). Real-time PCR (RT-PCR) was conducted to determine the expression levels of UL9, UL30, UL42 of HSV-1/F and at 2, 3 and 4 h.p.i, respectively. The primer pairs were the same as described above.

\section{Protein docking stimulation}

ZDock (http://zdock.umassmed.edu/) was manipulated to predict the structures of protein-protein interaction and symmetric multimers. Prediction of protein-protein interaction was in three steps as follows ${ }^{[12]}$. Firstly input ligand and receptor protein structures and choose the ZDock version options; Secondly select the blocking/contacting residues; Thirdly view docking results online or download in Pymol. Binding affinity $(\Delta G)$ and dissociation constant $\left(K_{d}\right)$ predicted values for the protein-protein interactions was obtained from docking results.

Molecular docking stimulation

LeDock (http://www.lephar.com/index.htm) was manipulated to stimulate the docking between small molecular compounds and proteins. Docking binding affinity $(\Delta \mathrm{G}) \otimes 0 \mathrm{~kJ} / \mathrm{mol}$ indicated ligand molecules can spontaneously bind to receptor proteins, while $(\Delta \mathrm{G}) \varangle 5 \mathrm{~kJ} / \mathrm{mol}$ indicated both of them can bind stably[13]. The target proteins in all networks were obtained 3D structures from the RCSB PDB database (http://www.rcsb.org/)[14]. 2D structures of all compounds was obtained from ZINC (http://zinc.docking.org/)[15]. Top10 docking complexes were docked between each protein and ligand, and chosen the complexes with the smallest binding energy.

\section{Co-immunoprecipitation (co-IP)}


HFF cells were infected with HSV-1 for $12 \mathrm{~h}$ in $100 \mathrm{~mm}^{2}$ flask dish, which were collected and lysed in 100 $\mu \mathrm{L}$ SDS Lysis Buffer (Beyotime, China) containing 1\% PMSF and centrifuged at $12,000 \mathrm{~g}$. The supernatant was divided into two parts, one for input and other was incubated with IgG (normal mouse or rabbit lgG, primary antibody) at $4^{\circ} \mathrm{C}$ overnight. Then the mixture was treated with $35 \mu \mathrm{L}$ of volume of Protein A/G magnetic beads at $4^{\circ} \mathrm{C}$ for $2 \mathrm{~h}$. Next, the immune-precipitates were collected, washed three time with PBS, and re-suspended in 30mL $1 *$ SDS-PAGE buffer (Beyotime, China). Finally, the samples were boiled for $10 \mathrm{~min}$ and analysed by western blotting.

\section{Plasmid transfection}

HEK293T cells seed in 12-well plates, and the second day the mentioned plasmids were performed with Lipofectamin-3000 transfection reagent according to the manufacturer's instructions (Invitrogen). Briefly, $500 \mathrm{ng}$ of the corresponding plasmids and Lipofectamine 3000 reagent were diluted in $100 \mu \mathrm{L}$ Opti-MEM I reduced serum medium (Invitrogen) and the diluted plasmids were then added to the Lipofectamine 3000 (1:1 ratio), mixed, and incubated at room temperature for $10 \mathrm{~min}$. The transfection mixture was then added to cells at $60-70 \%$, and was replaced with flesh $2 \%$ FBS DMEM after transfection $6 \mathrm{~h}$.

\section{Western blotting}

HFF cells were seeded in 12-well plates with the density of $1.5 \times 10^{6}$ cells/ well. Until $85 \%$ cell confluence, cells were infected with HSV-1 $(\mathrm{MOI}=20)$ at $37^{\circ} \mathrm{C}$ for $4 \mathrm{~h}$. Therefore, DMEM maintenance medium with or without AT-533 or 17-AAG was added. At $12 \mathrm{~h}$ post infection, the cells were washed three times with PBS, and were lysed with $1 *$ SDS-PAGE buffer (Beyotime). The equal amount ( $40 \mu \mathrm{g} / \mathrm{sample}$ ) proteins were subjected to Western Blot analysis.

\section{Immunofluorescence assay}

HFF cells were cultured in 12-wells plates, and second day cells infected with $\mathrm{HSV}-1(\mathrm{MOI}=20)$ at $37^{\circ} \mathrm{C}$ for $4 \mathrm{~h}$ for viral DNA replication. Cells were transferred into maintain medium with or without AT-533 or 17AAG and incubated for $8 \mathrm{~h}$. Cells were fixed for $15 \mathrm{~min}$ with $4 \%$ paraformaldehyde (PFA) and permeabilized with $0.01 \%$ Triton X-100 for $5 \mathrm{~min}$, and subsequently incubated with anti-UL42 antibody (Abcam) at $4{ }^{\circ} \mathrm{C}$ overnight and Alexa Fluor 488 (1:1000) secondary antibody (Invitrogen) at room temperature for $1 \mathrm{~h}$. After each step the slides were washed triplicate with PBS, and which finally were preserved with PBS. Finally, the nuclear staining with 4,6-diamidino-2-phenylindole (DAPI, Molecular Probes) was performed for $15 \mathrm{~min}$. Fluorescence was recorded in a fluorescence microscopy (Canon).

\section{Statistical analysis}

Research data were calculated as the mean $\pm S D$, and statistical significance were determined by the student's $t$ test. The statistical significance were determined by $P$ values $(P<0.05)$. More than three times was performed at each time.

\section{Results}




\section{Cytotoxicity and anti-HSV-1 activity of AT-533 and 17-AAG}

To examine the cytotoxic effect of two potent Hsp90 inhibitors AT-533 and 17-AAG on HFF cells, CCK-8 assay was used. Different concentrations of Hsp90 inhibitors were used. AT-533 exhibited a larger cytotoxicity than 17-AAG (Fig. 1A), and achieved $\mathrm{TC}_{50}$ (50\% toxicity concentrations) of AT-533 and 17AAG (Table 1). Hence, to examine the antiviral activities of these Hsp90 inhibitors, CPE (virus-induced cytopathic effect) reduction assay was used $[11,16,17]$. AT-533 $(0.125 \mu \mathrm{M})$ and 17-AAG $(0.20 \mu \mathrm{M})$ exhibited reasonable inhibition of induced CPE (Fig. 1B). To further clarify the antiviral effect of Hsp90 inhibitors, obtaining $\mathrm{IC}_{50}$ (50\% inhibition concentrations) in Table 1,antiviral assay of GFP-HSV-1 was used (Fig. 1C)[10, 18]. Morphologically, gradient Hsp90 inhibitors were exhibited well recovery of HSV-1 cytopathic effects with concentration dependent (Fig. 1D). We next investigated anti-GFP-HSV-1 efficacy of HFF cell. GFP-HSV-1 was used to infect cells and the Hsp90 inhibitors were treated at the same time. Infected cells were imaged using a fluorescence microscope at 12h.p.i, and the treatment of Hsp90 inhibitors had preferable fluorescence inhibition with concentration dependent (Fig. 1E).

Table 1

Cytotoxicity, anti-HSV-1 activity and TI of AT-533 and 17-AAG

\begin{tabular}{|llll|}
\hline Hsp90 inhibitors & TC50 $(\mu \mathrm{M})$ & $\mathrm{IC50}(\mu \mathrm{M})$ & $\mathrm{TI}$ \\
\hline 17-AAG & $14.24 \pm 0.26$ & $0.30 \pm 0.20$ & $47.90 \pm 1.87$ \\
\hline AT-533 & $1.37 \pm 0.32$ & $0.05 \pm 0.01$ & $25.35 \pm 1.03$ \\
\hline
\end{tabular}

\section{Regulation of HSV-1 replication phase}

Next, we analyzed regulation of HSV-1 replication phase was affected by Hsp90 inhibitors AT-533 and 17AAG.The detection of DNA synthesis was performed to demonstrate that AT-533 and 17-AAG significantly reduced genome copy production (Fig. 2A).To evaluate whether Hsp90 exerts specific function in HSV-1 immediately early and early life cycle, AT-533 and 17-AAG were added at 1h.p.i and obtained at different time points (2 $\sim 6$ h.p.i) in HSV-1-infected HFF cells (Fig. 2B).Cell monolayers were then fixed and extracted DNA, both inhibitors significantly reduced the HSV-1 DNA production at different time points(2 $\sim 6$ h.p.i). Notably, HSV-1 that was not treated with Hsp90 inhibitors started to replicate in large numbers at 4h.p.i (Fig. 2C). Besides, to analyze the effects of Hsp90 inhibitors on HSV-1 gene expression, the mRNA expression levels of viral immediate-early gene (a0) were quantified at $3 \sim 6 \mathrm{~h} . \mathrm{p} . \mathrm{i}$, respectively (Fig. 2D). Both AT-533 and 17-AAG treatment significantly reduced the mRNA expression of viral immediate-early gene ( $\mathrm{a} 0$ ). To further clarified whether Hsp90 exerts directly or indirectly function in HSV1 replication phase, AT-533 and 17-AAG were added at different time points(2,3,4h.p.i) and obtained at 12h.p.i(Fig. 2D). Hsp90 inhibitors treatment both significantly reduced the DNA copy number of UL9,UL30 and UL42(Fig. 2D).Interestingly, Hsp90 inhibitors treatment could not reduce the mRNA expression of viral gene UL9,UL30 and UL42 at 4h.p.i and significantly reduced at 2,3h.p.i Generally, HSV-1 treated in HFF cells largely initiated DNA replication at 4h.p.i, meanwhile Hsp90 inhibitors treatment directly reduced DNA copy numbers instead influencing viral gene transcriptions. 
A.HFF cells was infected with HSV-1 $(\mathrm{MOI}=1)$ and extracted viral DNA to assess infectious and progeny virus DNA copy number at 12, 24, 48, 72h.p.i B. Diagrammatic sketch of time-addition assay to assess HSV-1 DNA copy number and mRNA expression. C.HSV-1 DNA copy number with or without AT-533 and 17-AAG was detected at different time points (2,3,4,5h.p.i). D.HSV-1 mRNA expression was detected at different time points (2,3,4,5h.p.i). E.Diagrammatic sketch of HFF cells treated with Hsp90 inhibitors in different time points to assess HSV-1 DNA copy number and mRNA expression. F.HFF cells was infected with HSV-1 $(\mathrm{MOI}=20)$ and treated with Hsp90 inhibitors at different time points (2,3,4h.p.i), and then viral DNA copy number was detected. G. HFF cells was infected with HSV-1 $(\mathrm{MOI}=20)$ and treated with Hsp90 inhibitors at different time points (2,3,4h.p.i), and then viral mRNA expression was detected.

\section{Interaction between Hsp90 and HSV-1 replication-related proteins}

In previous researches, Hsp90 inhibitor geldanamycin induced the abnormal location of HSV-1 DNA polymerase catalytic submit UL30, however few direct experimental evidences proved the interaction between Hsp90 and UL30 or other replication-related proteins[7]. Thus, we further investigated the interaction and function between Hsp90 and HSV-1 replication-related protein.To prepare for the protein modeling and construct the viral proteins model, phylogenetic analysis of HSV-1 DNA polymerase UL30 and UL42 were individually retrieved from GenBank and showed in Fig. 3A\&B. The crystal structure of DNA polymerase catalytic subunit UL30 (PDB:2GV9) and processivity factor UL42 model from Swissmodel (PDB:1DML) interacted with Hsp90 (PDB:4BQG) were protein docking stimulated(Fig. 3C\&D). Hence, Homology analysis of HSV-1 $U_{L} 30 / 42$ and other Herpesviridae DNA polymerase were exhibited(Table $2 \& 3)$. Altogether, the binding affinity $(\Delta G)$, dissociation constant $\left(K_{d}\right)$ (Table 4) and higher number of protein-protein contacts (Table 5) between Hsp90 and viral proteins were showed. In conclusion, protein docking stimulation were proved that Hsp90 interact with both UL30 and UL42. To further confirm the interaction between Hsp90 and HSV-1 DNA polymerase, co-IP assay were manipulated (Fig. 3E).HFF infected with HSV-1 treatment with DMSO were indicated Hsp90 interact with UL42, and at the same time treated with 17-AAG were indicated the reducing interaction between Hsp90 and UL42.In short,Hsp90 interacted with HSV-1 DNA polymerase UL42 via protein docking stimulation and CO-IP assay.Because of the insufficiency of commercial HSV-1 UL30 antibody,the interaction between Hsp90 and UL30 is still need further studies. 
Table 2

Homology analysis of HSV- $1 U_{L} 30$ and other Herpesviridae DNA polymerase catalytic subunit

\begin{tabular}{|lll|}
\hline Description & Query Cover & Percent Identity \\
\hline HSV-2 UL30 & $100 \%$ & $90.40 \%$ \\
\hline HHV-3/VZV ORF28 & $95 \%$ & $55.42 \%$ \\
\hline HHV-4/ZBV BALF5 & $92 \%$ & $41.75 \%$ \\
\hline HHV-5/HCMV U 54 & $82 \%$ & $34.81 \%$ \\
\hline HHV-6 Pol & $92 \%$ & $31.21 \%$ \\
\hline HHV-7 Pol & $93 \%$ & $31.81 \%$ \\
\hline HHV-8/KSHV Pol & $95 \%$ & $55.42 \%$ \\
\hline
\end{tabular}

Table 3

Homology analysis of HSV- $1 \mathrm{U}_{\mathrm{L}} 42$ and other Herpesviridae DNA polymerase processivity factor

\begin{tabular}{|lll|}
\hline Description & Query Cover & Percent Identity \\
\hline HSV-2 UL42 & $100 \%$ & $71.14 \%$ \\
\hline HHV-3/VZV ORF16 & $56 \%$ & $25.44 \%$ \\
\hline HHV-5/HCMV UL44 & $9 \%$ & $40 \%$ \\
\hline HHV-6 p41 & $2 \%$ & $50 \%$ \\
\hline HHV-7 U27 & $10 \%$ & $32.50 \%$ \\
\hline HHV-8/KSHV PF-8 & $19 \%$ & $39.58 \%$ \\
\hline
\end{tabular}


Table 4

Binding affinity $(\Delta \mathrm{G})$ and dissociation constant $\left(\mathrm{K}_{\mathrm{d}}\right)$ predicted values for the interaction between viral proteins and $\mathrm{Hsp} 90 \beta$

\begin{tabular}{|c|c|c|c|c|c|}
\hline Complex & Subtype & $\Delta G\left(\right.$ Kcal mol$\left.^{-1}\right)$ & $\begin{array}{l}\text { Mean } \Delta G \\
\left(K_{c a l ~ m o l}-1\right)\end{array}$ & $\begin{array}{l}\mathrm{K}_{\mathrm{d}}(\mathrm{M}) \\
\text { at } 25^{\circ} \mathrm{C}\end{array}$ & Mean $\mathrm{K}_{\mathrm{d}}(\mathrm{M})$ at $25^{\circ} \mathrm{C}$ \\
\hline Hsp90 \& BALF5 & Hsp90ß & -9.3 & -9.3 & $1.4 \mathrm{E}-07$ & 1.4E-07 \\
\hline \multirow[t]{2}{*}{ Hsp90 \& AKT } & Hsp90a & -20.0 & \multirow[t]{2}{*}{-15.55} & 2.3E-15 & \multirow[t]{2}{*}{$4.5 \mathrm{E}-12$} \\
\hline & Hsp90ß & -11.1 & & 6.7E-09 & \\
\hline \multirow[t]{2}{*}{ Hsp90 \& $U_{L} 30$} & Hsp90a & -11.6 & \multirow[t]{2}{*}{-13.35} & $3.2 \mathrm{E}-09$ & \multirow[t]{2}{*}{$5.8 \mathrm{E}-11$} \\
\hline & Hsp90ß & -15.1 & & $8.3 \mathrm{E}-12$ & \\
\hline \multirow[t]{2}{*}{ Hsp90 \& U 42} & Hsp90a & -14.2 & \multirow[t]{2}{*}{-13.25} & $3.9 \mathrm{E}-11$ & \multirow[t]{2}{*}{$2.5 \mathrm{E}-10$} \\
\hline & Hsp90ß & -12.3 & & 1.0E-09 & \\
\hline
\end{tabular}

Table 5

Number of protein-protein contacts (PPC) between viral proteins and Hsp90 $\beta$

\begin{tabular}{|c|c|c|c|c|c|c|c|}
\hline \multirow{2}{*}{$\begin{array}{l}\text { Complex } \\
\text { Subtype }\end{array}$} & \multirow{2}{*}{$\begin{array}{l}\text { Hsp90 \& } \\
\text { BALF5 } \\
\text { Hsp90ß }\end{array}$} & \multicolumn{2}{|c|}{ Hsp90 \& AKT } & \multicolumn{2}{|c|}{ Hsp90 \& U 30} & \multicolumn{2}{|c|}{ Hsp90 \& U 42} \\
\hline & & Hsp90a & Hsp90ß & Hsp90a & Hsp90ß & Hsp90a & Hsp90ß \\
\hline $\begin{array}{l}\text { ICs charged- } \\
\text { charged }\end{array}$ & 2 & 14 & 12 & 12 & 11 & 13 & 6 \\
\hline ICs charged-polar & 8 & 25 & 15 & 23 & 19 & 15 & 8 \\
\hline ICs charged-apolar & 8 & 81 & 20 & 42 & 45 & 37 & 25 \\
\hline ICs polar-polar & 6 & 4 & 5 & 4 & 6 & 6 & 1 \\
\hline ICs polar-apolar & 25 & 25 & 21 & 12 & 33 & 24 & 20 \\
\hline ICs apolar-apolar & 28 & 32 & 15 & 21 & 29 & 33 & 23 \\
\hline $\begin{array}{l}\text { Total Number of } \\
\text { Contacts }\end{array}$ & 77 & 181 & 88 & 114 & 143 & 128 & 83 \\
\hline $\begin{array}{l}\text { Mean Number of } \\
\text { Contacts }\end{array}$ & 77 & 134 & & 128 & & 105 & \\
\hline
\end{tabular}

\section{Effects of AT-533 and 17-AAG on UL42 protein expression}

In order to determine whether AT-533 and 17-AAG affect viral DNA replication by affecting UL42 protein expression, analysis was performed by Western blotting. HFF cells were infected with HSV-1 $(\mathrm{MOI}=20)$ and treated with or without AT-533 or 17-AAG, while proteins were extracted at different time points $(2,4$, 6, 8,h.p.i) showed in Fig. 4A. Hsp90 inhibitors treatment reduced the protein expression of viral early 
proteins UL42 and host protein AKT instead of influencing the protein expression of Hsp90 and ICP8, which indicated Hsp90 inhibitors blocked the activity of Hsp90 and reduced the client protein expression of UL42 instead of ICP8. Interestingly, Hsp90 inhibitors reduced the protein expression of UL42 only in early stage(2,4h.p.i) rather than 6,8h.p.i, which was consistent with time-addition DNA and mRNA detection. To further confirm the key time point of Hsp90 affecting DNA replication, HFF cells synchronously treated with HSV-1 $(\mathrm{MOI}=20)$ and Hsp90 inhibitors at 4h.p.i as showed in Fig. 4B, AT-533 and 17-AAG didn't affect the protein expression of ICP8 and affected UL42 indeed. To prepare plasmids transfection in HEK293T cells, the cytotoxicity detection of AT-533 and 17-AAG in HEK293T were assayed (Fig. 4B).To prepare the plasmid transfection in HEK293T cells, the CCK8 assay of AT-533 and 17-AAG in HEK293T cells are used. AT-533 exhibited a larger cytotoxicity than 17-AAG which was showed in Fig. 4C. HEK293T cells were transfected with HA-UL42 and HA-Vector plasmid, and at 6 h.p.i flash 2\% DMEM were added with and without AT-533 or 17-AAG.AT-533 and 17-AAG treatment reduced the HA-UL42 expression and didn't affect the transfection of HA-Vector (Fig .4D).Consistently, the results of immunofluorescence assay was the same as western blotting of HA-UL42 transfection treated with Hsp90 inhibitors(Fig. 4E).Verifying the functionality and importance of HA-UL42 plasmid in HEK293T cells, which were first infected with HSV-1 (MOI = 20) with or without Hsp90 inhibitors, and transfected with HAUL42 to detect DNA production(Fig. 4F). Over-expression of HA-UL42 in HSV-1 infection with AT-533 and 17-AAG could restore the Hsp90 inhibitors inducing DNA replication reduction. In short, AT-533 and 17AAG via suppressing viral and plasmid UL42 expression hindered HSV-1 DNA replication.

\section{Hsp90 inhibition induced autophagy-mediated degradation of UL42}

Next, we attempted to identify the specific mechanisms responsible for the Hsp90 inhibition-induced UL42 degradation. In our previous study and those of others, Hsp90 client proteins were degraded via two main ways such as ubiquitination-proteasome pathway and autophagy-induced pathway. Hence, we first assessed the levels of ubiquitinated proteins in HFF cells treated with different Hsp90 inhibitors and found that all treatments did not accumulate the polyubiquitin proteins(Fig. 5A). Besides, the proteasome inhibitors MG-132 was treated and did not restore the UL42 reduction of Hsp90 inhibitors inducing. Consistently, HEK293T cells also were treated with or without Hsp90 inhibitors and MG-132, which was not restored the reduction of HA-UL42 (Fig. 5B). To examined whether Hsp90 inhibition-induced UL42 degradation was dependent on the autophagy pathway. HFF cells were infected with HSV-1 $(\mathrm{MOI}=20)$ and treated with or without concentration gradient Hsp90 inhibitors and Chloroquine (CQ), an inhibitor of

the fusion of the lysosome and autophagosome. Chloroquine (CQ) could reverse the degradation of UL42 mediated by Hsp90 inhibition (Fig. 5C).Similarly,HEK293 cells were transfected with HA-UL42 and treated with Hsp90 inhibitors and CQ, as a result CQ treatment restored the degradation of UL42 (Fig. 5D).

\section{Effects of AT-533 and 17-AAG on helicase-primase UL5/8/52}


HSV- 1 helicase-primase UL5/8/52 have the function of untying DNA double strands and coordinating the synthesis of leading and lagging chains. It is also indispensable for DNA proper and efficient synthesis. Therefore, to further examine the effect of AT-533 and 17-AAG on helicase-primase UL5/8/52, the immunofluorescence assay was used. HEK293T cells were transfected with Flag-UL5 and treated with or with AT-533 and 17-AAG after 6 hours post transfection. Hsp90 inhibitors didn't affect the protein expression of UL5 as showed in Fig. 6A. Consistently, Hsp90 inhibitors treatment were not reduced the protein expression of HA-UL8 and EGFP- UL52 (Fig. 6B\&C).

\section{Effects of AT-533 and 17-AAG on ACV-resistant HSV-1}

Finally, we evaluated the potent antiviral activity of AT-533 and 17-AAG on ACV-resistant HSV-1 via performing viral titer determination and DNA synthesis detection. Vero cells were infected with HSV-1/153 $(\mathrm{MOI}=1)$ and Hsp90 inhibitors, after 24h.p.i were extracted to analysis viral titer (Fig. 7A). Indeed, AT-533 and 17-AAG treatment reduced the viral titer of HSV-1/153 with favorable concentration dependent. Therefore, the extraction from above was manipulated for viral DNA detection (Fig. 7B). In addition, AT533 and 17-AAG reduced the DNA production of HSV-1/153.Consistently, AT-533 and 17-AAG treatment reduced the viral titer and DNA production of HSV-1/Blue (Fig. 7C\&D). Among these data, Hsp90 inhibitors induced degradation of UL42 may played critical roles in antiviral activities of ACV-resistant HSV-1.

\section{Discussion}

Several studies have demonstrated that Hsp90 participates in many HSV-1 infectious stages including early and late stages, which indicated Hsp90 is a promising candidate of novel drug targets[19]. In our laboratory, previous studies found that Hsp90 could promote capsid protein nuclear transport via interacting with acetylated a-tubulin[20]. Further, Hsp90a knockdown or inhibition treated with 17-AAG and SNX-2112 significantly inhibited the promoter activity of HSV-1 a genes via destroying the stability of VP16[21]. In addition, novel Hsp90 inhibitor AT-533 could hinder HSV-1 nuclear egress and assembly[22]. Many studies have described the function of Hsp90 in HSV-1 DNA replication stage. For example, Hsp90 inhibitor geldanamycin reduced viral titers and induced the abnormal location of HSV-1 DNA polymerase catalytic subunit $\mathrm{pU}_{\mathrm{L}} 30[7,23]$. However, the function of Hsp90 inhibitors and the interaction of Hsp90 between other HSV-1 replication-related proteins is still unknown.

In particular, it has been reported that Hsp90 has a regulatory roles in different virus particularly in DNA replication stages including DNA viruses, negative chain RNA virus and double chain RNA viruses[24]. ORF29F, is a single-stranded DNA binding protein in Varicella-zoster virus (VZV), whose nucleic localization is depend in the activity of Hsp90[25]. Nuclear transport of epstein-barr virus (EBV) DNA polymerase catalytic subunit BALF5 is dependent on the molecular chaperone Hsp90[26]. Hence, the formation of dengue virus DNA polymerase NS5 protein was required by Hsp90[27]. These findings indicated that Hsp90 likely plays important roles in viral replication. In previous research, Hsp90 inhibitors geldanamycin induced the abnormal location of HSV-1 DNA polymerase catalytic subunit $\mathrm{pU}_{\mathrm{L}} 30$ indeed. 
However, explicit and direct research data of interaction between Hsp90 and UL30 is absent. Hence, in this study we focused on elucidating the role and specific mechanism of Hsp90 inhibitors in DNA replication phase, and assessing the antiviral activity especially in ACV-resistant strains.

CPE assay and GFP-HSV-1 antiviral experiment showed that Hsp90 inhibitors AT-533 and 17-AAG had a significant antiviral effect in a concentration-dependent manner. Time-addition assay infected with HSV-1 and treated with or without AT-533 and 17-AAG, which indicated deletion of Hsp90 activity reducing the viral titer and infectious DNA copy number. Detection of viral gene expression and DNA copy number in different time point indicated that Hsp90 inhibitors treatment directly blocked DNA replication instead of influencing viral gene expression at 4 h.p.i.

The three-dimensional and atomic structures of protein complexes can provide useful information for protein engineering, systems biology, drug design, and understanding pathology. If the structures of the subunits are known, then it is benefited to model the complex computationally[28]. Protein docking stimulation was first manipulated in this study, which indicated Hsp90 may both interact with DNA polymerase catalytic subunit UL30 and processivity factor UL42. Therefore, co-immunoprecipitation experiment confirmed that UL42 interacted with Hsp90 as its client proteins. Moreover, through Western blotting and immunofluorescence assay, Hsp90 inhibitors induces the degradation of virus and plasmidexpressed $\mathrm{pU}_{\mathrm{L}} 42$ via autophagy pathway, and over expression of $\mathrm{pU}_{\mathrm{L}} 42$ can revert HSV-1 DNA copy number. Through Western blotting and immunofluorescence experiments, Hsp90 inhibitors could not affect the expression of HSV-1 helicase-primerase, further highlighting the indispensable role of Hsp90 inhibitors regulating HSV-1 DNA polymerase processivity factor $\mathrm{pU}_{\mathrm{L}} 42$ in DNA replication phase.

The abuse of acyclovir and its derivatives caused the gene mutation of HSV-1 Thymokinase (TK) and DNA polymerase UL30, as a consequence ACV-resistant strains was bloomed dramatically[29, 30]. Notably, Hsp90 inhibitors AT-533 and 17-AAG reduced the viral titer and infectious DNA production of ACV-resistant strains (HSV-1/106 and HSV-1/Blue). The DNA polymerase processivity factor UL42 may play a indispensable roles in antiviral effect upon ACV-resistant strains, which is still need to further explore and research.

\section{Conclusion}

Summarizing these data, novel Hsp90 inhibitor AT-533 is assessed to be a potential candidate at HSV-1 replication phase, especially for ACV-resistant strains. First of all, the time-addition detection of DNA copy number and mRNA expression indicated Hsp90 inhibitors AT-533 and 17-AAG directly block HSV-1 DNA replication phase. Secondly, protein docking stimulation and co-immunoprecipitation approved pUL42 interacted with Hsp90 as its client proteins. Besides, the results of western blot indicated Hsp90 inhibitors AT-533 and 17-AAG induced the degradation of pUL42 via autophagy pathway. Finally, Hsp90 inhibitors AT-533 and 17-AAG exhibited favorable antiviral activity towards ACV-assistant strains, which indicated pUL42 may be an antiviral active target for ACV-assistant strains. Comparing with previous work, this study identified pUL42 as a Hsp90 client protein in the HSV-1 replication stage and potential antiviral 
active target for ACV-assistant strains. It laid a solid theoretical foundation for other scholars to develop new anti-virus strategies and agents by focusing pUL42 as anti-virus targets.

\section{Abbreviations}

ACV: Acyclovir; Co-IP: Coimmunoprecipitation; CPE: Cytopathic effect; DMEM: Dulbecco's modified Eagle's medium; DMSO: Dimethyl sulfoxide; HSV-1: Herpes simplex virus 1; MOI: Multiplicity of infection; PBS: Phosphatebuffered saline; TCID50: 50\% tissue culture infective dose.

\section{Declarations}

\section{Ethics approval and consent to participate}

Not applicable.

\section{Consent for publication}

Not applicable.

\section{Availability of data and materials}

All relevant source data is available from the corresponding authors upon request.

\section{Competing interests}

The authors declare that they have no competing interests.

\section{Funding}

This work was supported by the National Natural Science Foundation of China (No. 81872908); Guangdong Provincial Key Laboratory of Virology; the Key Laboratory of bioengineering drugs of Guangdong Province of China.

\section{Authors' contributions}

WYF, RZ and QSR formulated the idea of the article and supervised the research. QSR and HX performed the research, analyzed the data and wrote the manuscript. QSR made contribution to the molecular docking. ZQZ, WZY, JJY and SXW participated in revising the data and improving manuscript writing. All authors reviewed the manuscript. And all authors read and approved the final version of the manuscript. 


\section{Acknowledgements}

We are grateful to Prof. Tao Peng (Guangzhou Institutes of Biomedicine and Health, Chinese Academy of Sciences) for providing mutant viruses HSV-1/BLUE and HSV-1/153 as well as the corresponding wildtype viruses for our studies.

\section{References}

1. Yoshikawa T. [The mechanisms for latency and reactivation of alpha herpesviridae]. Nihon Rinsho. 2000;58:807-14.

2. Kennedy PG, Rovnak J, Badani H, Cohrs RJ. A comparison of herpes simplex virus type 1 and varicella-zoster virus latency and reactivation. J Gen Virol. 2015;96:1581-602. https://doi.org/10.1099/vir.0.000128.

3. James SH, Larson KB, Acosta EP, Prichard MN. Helicase-primase as a target of new therapies for herpes simplex virus infections. Clin Pharmacol Ther. 2015;97:66-78. https://doi.org/10.1002/cpt.3.

4. Souza TM, De Souza MC, Ferreira VF, Canuto CV, Marques IP, Fontes CF, Frugulhetti IC: Inhibition of HSV-1 replication and HSV DNA polymerase by the chloroxoquinolinic ribonucleoside 6-chloro-1,4dihydro-4-oxo-1-(beta-D-ribofuranosyl) quinoline-3-carboxylic acid and its aglycone. Antiviral Res 2008, 77:20-27.https://doi.org/10.1016/j.antiviral.2007.08.011.

5. Piret J, Boivin G. Resistance of herpes simplex viruses to nucleoside analogues: mechanisms, prevalence, and management. Antimicrob Agents Chemother. 2011;55:459-72. https://doi.org/10.1128/AAC.00615-10.

6. Wang Y, Jin F, Wang R, Li F, Wu Y, Kitazato K, Wang Y. HSP90: a promising broad-spectrum antiviral drug target. Arch Virol. 2017;162:3269-82. https://doi.org/10.1007/s00705-017-3511-1.

7. Burch $A D$, Weller SK. Herpes simplex virus type 1 DNA polymerase requires the mammalian chaperone hsp90 for proper localization to the nucleus. J Virol. 2005;79:10740-9. https://doi.org/10.1128/JVI.79.16.10740-10749.2005.

8. Wang Y, Wang Q, Zhu Q, Zhou R, Liu J, Peng T. Identification and characterization of acyclovirresistant clinical HSV-1 isolates from children. J Clin Virol. 2011;52:107-12. https://doi.org/10.1016/j.jcv.2011.06.009.

9. Ramakrishnan MA. Determination of $50 \%$ endpoint titer using a simple formula. World $\mathrm{J}$ Virol. 2016;5:85-6. https://doi.org/10.5501/wjv.v5.i2.85.

10. Alvarez DM, Duarte LF, Corrales N, Smith PC, Gonzalez PA. Cetylpyridinium chloride blocks herpes simplex virus replication in gingival fibroblasts. Antiviral Res. 2020;179:104818. https://doi.org/10.1016/j.antiviral.2020.104818.

11. Bonvicini F, Lianza M, Mandrone M, Poli F, Gentilomi GA, Antognoni F. Hemidesmus indicus (L.) R. Br. extract inhibits the early step of herpes simplex type 1 and type 2 replication. New Microbiol. 2018;41:187-94. 
12. Pierce BG, Wiehe $K$, Hwang H, Kim BH, Vreven T, Weng Z. ZDOCK server: interactive docking prediction of protein-protein complexes and symmetric multimers. Bioinformatics. 2014;30:1771-3. https://doi.org/10.1093/bioinformatics/btu097.

13. He D, Huang JH, Zhang ZY, Du Q, Peng WJ, Yu R, Zhang SF, Zhang SH, Qin YH. A Network Pharmacology-Based Strategy For Predicting Active Ingredients And Potential Targets Of LiuWei DiHuang Pill In Treating Type 2 Diabetes Mellitus. Drug Des Devel Ther. 2019;13:3989-4005. https://doi.org/10.2147/DDDT.S216644.

14. Burley SK, Berman HM, Bhikadiya C, Bi C, Chen L, Di Costanzo L, Christie C, Dalenberg K, Duarte JM, Dutta S, et al. RCSB Protein Data Bank: biological macromolecular structures enabling research and education in fundamental biology, biomedicine, biotechnology and energy. Nucleic Acids Res. 2019;47:D464-74. https://doi.org/10.1093/nar/gky1004.

15. Sterling T, Irwin JJ. ZINC 15-Ligand Discovery for Everyone. J Chem Inf Model. 2015;55:2324-37. https://doi.org/10.1021/acs.jcim.5b00559.

16. Bag P, Chattopadhyay D, Mukherjee H, Ojha D, Mandal N, Sarkar MC, Chatterjee T, Das G, Chakraborti S. Anti-herpes virus activities of bioactive fraction and isolated pure constituent of Mallotus peltatus: an ethnomedicine from Andaman Islands. Virol J. 2012;9:98. https://doi.org/10.1186/1743-422X-998.

17. Mukherjee H, Ojha D, Bag P, Chandel HS, Bhattacharyya S, Chatterjee TK, Mukherjee PK, Chakraborti S, Chattopadhyay D. Anti-herpes virus activities of Achyranthes aspera: an indian ethnomedicine, and its triterpene acid. Microbiol Res. 2013;168:238-44. https://doi.org/10.1016/j.micres.2012.11.002.

18. Iqbal A, Suryawanshi R, Yadavalli T, Volety I, Shukla D. BX795 demonstrates potent antiviral benefits against herpes simplex Virus-1 infection of human cell lines. Antiviral Res. 2020;180:104814. https://doi.org/10.1016/j.antiviral.2020.104814.

19. Li Z, Li L, Zhou H, Zeng L, Chen T, Chen Q, Zhou B, Wang Y, Chen Q, Hu P, Yang Z: Radix isatidis Polysaccharides Inhibit Influenza a Virus and Influenza A Virus-Induced Inflammation via
Suppression of Host TLR3 Signaling In Vitro. Molecules (Basel, Switzerland) 2017, 22.https://doi.org/10.3390/molecules22010116.

20. Zhong M, Zheng K, Chen M, Xiang Y, Jin F, Ma K, Qiu X, Wang Q, Peng T, Kitazato K, Wang Y. Heatshock protein 90 promotes nuclear transport of herpes simplex virus 1 capsid protein by interacting with acetylated tubulin. PLoS One. 2014;9:e99425. .https://doi.org/10.1371/journal.pone.0099425.

21. Wang Y, Wang R, Li F, Wang Y, Zhang Z, Wang Q, Ren Z, Jin F, Kitazato K, Wang Y. Heat-shock protein 90alpha is involved in maintaining the stability of VP16 and VP16-mediated transactivation of alpha genes from herpes simplex virus-1. Mol Med. 2018;24:65. https://doi.org/10.1186/s10020-018-0066$\mathrm{x}$.

22. Li F, Jin F, Wang Y, Zheng D, Liu J, Zhang Z, Wang R, Dong D, Zheng K, Wang Y. Hsp90 inhibitor AT533 blocks HSV-1 nuclear egress and assembly. J Biochem. 2018;164:397-406. https://doi.org/10.1093/jb/mvy066. 
23. Li YX, Liu M, Li X, Tang H. [The genes associated with geldanamycin inhibiting replication of herpes simplex virus type 1]. Bing Du Xue Bao. 2008;24:208-12.

24. Geller R, Taguwa S, Frydman J. Broad action of Hsp90 as a host chaperone required for viral replication. Biochim Biophys Acta. 2012;1823:698-706. https://doi.org/10.1016/j.bbamcr.2011.11.007.

25. Kyratsous CA, Silverstein SJ. BAG3, a host cochaperone, facilitates varicella-zoster virus replication. J Virol. 2007;81:7491-503. https://doi.org/10.1128/JVI.00442-07.

26. Kawashima D, Kanda T, Murata T, Saito S, Sugimoto A, Narita Y, Tsurumi T. Nuclear transport of Epstein-Barr virus DNA polymerase is dependent on the BMRF1 polymerase processivity factor and molecular chaperone Hsp90. J Virol. 2013;87:6482-91. https://doi.org/10.1128/JVI.03428-12.

27. Cabrera-Hernandez A, Thepparit C, Suksanpaisan L, Smith DR. Dengue virus entry into liver (HepG2) cells is independent of hsp90 and hsp70. J Med Virol. 2007;79:386-92. https://doi.org/10.1002/jmv.20786.

28. Moal IH, Chaleil RAG, Bates PA. Flexible Protein-Protein Docking with SwarmDock. Methods Mol Biol. 2018;1764:413-28. https://doi.org/10.1007/978-1-4939-7759-8_27.

29. Andrei G, Snoeck R. Herpes simplex virus drug-resistance: new mutations and insights. Curr Opin Infect Dis. 2013;26:551-60. https://doi.org/10.1097/QC0.0000000000000015.

30. Burrel S, Deback C, Agut H, Boutolleau D. Genotypic characterization of UL23 thymidine kinase and UL30 DNA polymerase of clinical isolates of herpes simplex virus: natural polymorphism and mutations associated with resistance to antivirals. Antimicrob Agents Chemother. 2010;54:4833-42. https://doi.org/10.1128/AAC.00669-10.

\section{Figures}




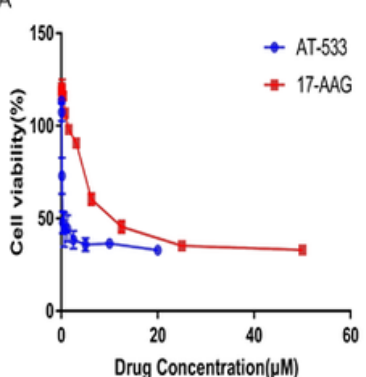

C

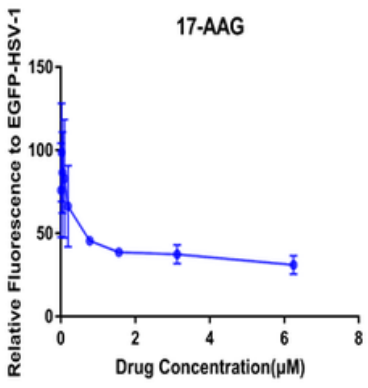

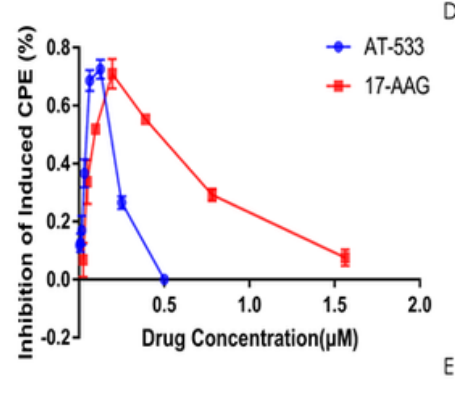

AT -533

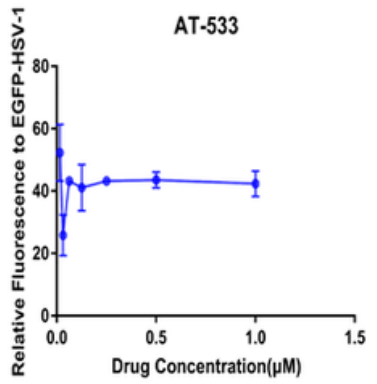

$E$
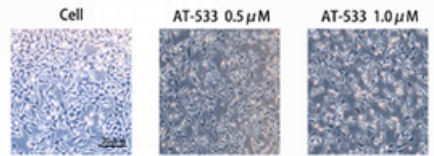

AT-533 $2.0 \mu \mathrm{M}$

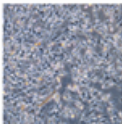

HSV-1 5 h.p. i

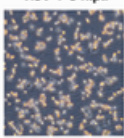

17-AAG $3.13 \mu \mathrm{M}$

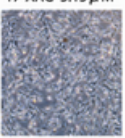

17-AAG $6.25 \mu \mathrm{M}$
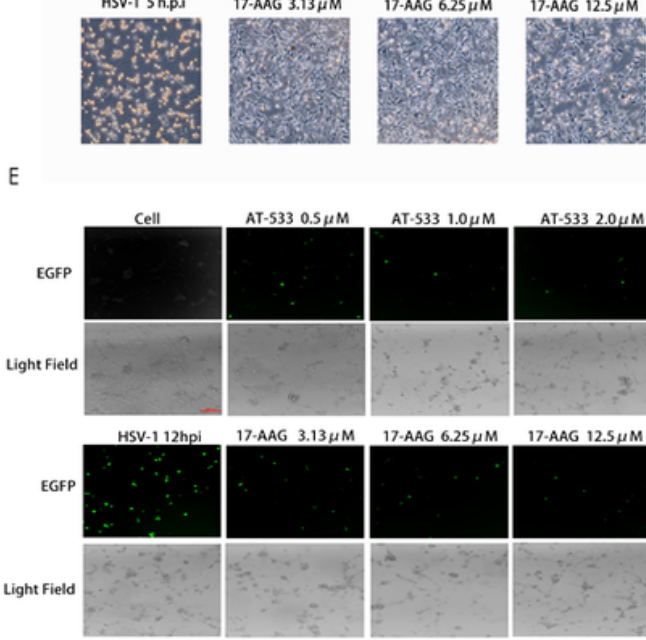

AT- $5330.5 \mu \mathrm{M}$

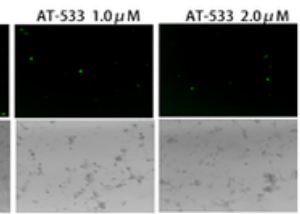

17-AAG $3.13 \mu \mathrm{M} \quad$ 17-AAG $6.25 \mu \mathrm{M} \quad$ 17-AAG $12.5 \mu \mathrm{M}$

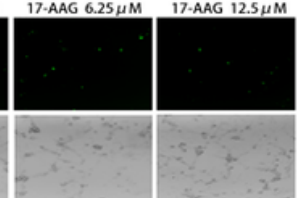

Figure 1 Cytotoxicities and anti-HSV-1 activities of AT-533 and 17-AAG A. Effects of AT-533 and 17-AAG of the viability for $48 \mathrm{~h}$ in HFF cells. B. CPEs antiviral assay of AT-533 and 17-AAG for $48 \mathrm{~h}$ in HFF cells. C.HFF cells was infected with EGFP-HSV-1 (MOI=20) and treated with AT-533 and 17-AAG.After infection 72 hours, relative fluorescence to EGFP-HSV-1 was assessed.

\section{Figure 1}

\section{Caption found in figure.}
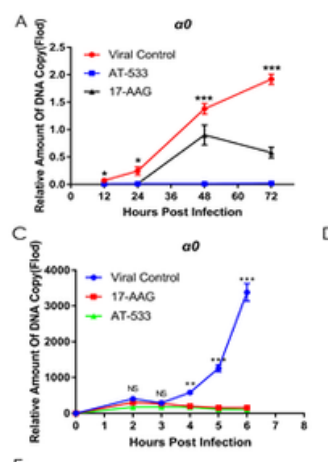

$\mathrm{D}$

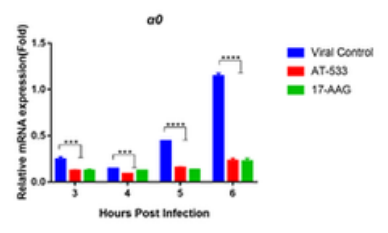

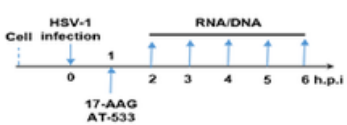

17.AAG
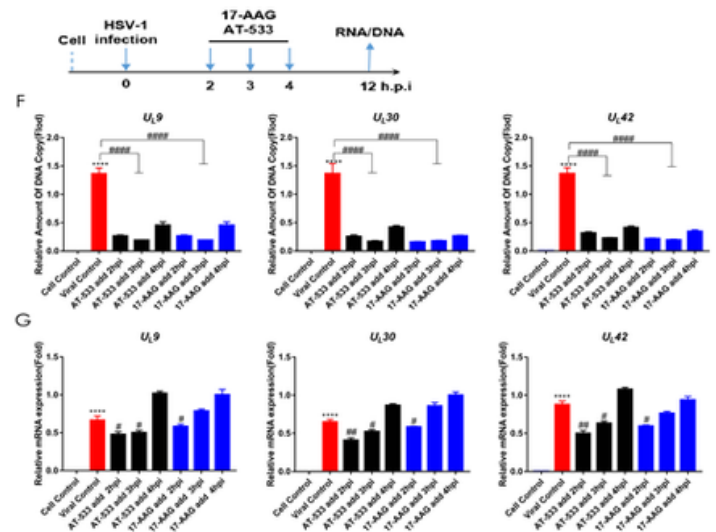

Figure 2 Hsp90 inhibitors directly blocked HSV-1 DNA replication A.HFF cells was infected with $\mathrm{HSV}-1(\mathrm{MOI}=1)$ and extracted viral DNA to assess infectious and progeny virus DNA copy number at $12,24,48$, 72h.p.i B. Diagrammatic sketch of time-addition assay to assess HSV-1 DNA copy number and mRNA expression. C.HSV-1 DNA copy number with or without AT-533 and 17-AAG was detected at different time points (2,3,4,5h.p.i). D.HSV-1 mRNA expression was detected at different time points $(2,3,4,5$ h.p.i). E.Diagrammatic sketch of HFF cells treated with Hsp90 inhibitors in different time points to assess HSV-1 DNA copy number and mRNA expression. F.HFF cells was infected with HSV1(MOI=20) and treated with Hsp90 inhibitors at different time points ( $2,3,4$ h.p.i), and then viral DNA copy number was detected. G. HFF cells was infected with $\mathrm{HSV}-1(\mathrm{MOI}=20)$ and treated with $\mathrm{Hsp} 90$ inhibitors at different time points (2,3,4h.p.i), and then viral mRNA expression was detected. 
Figure 2

Caption found in figure.

A
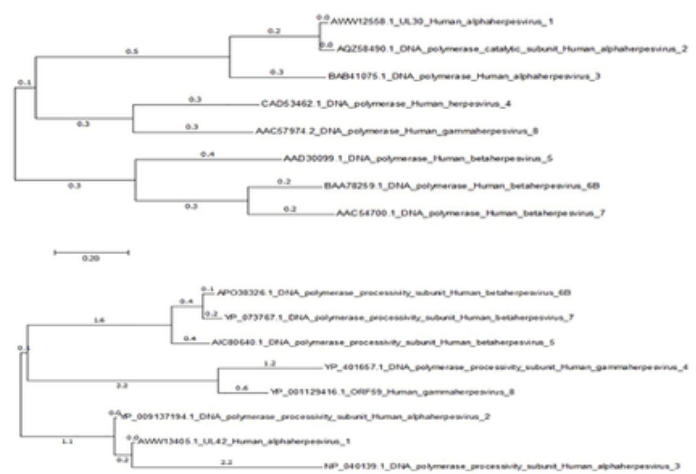

c

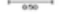
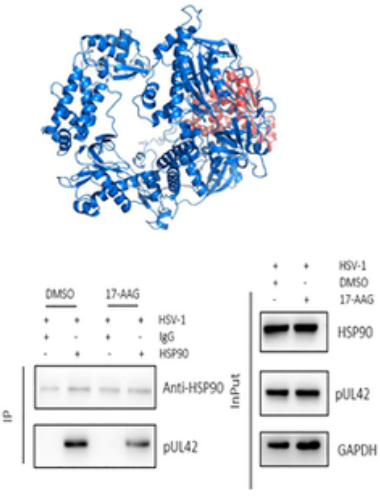

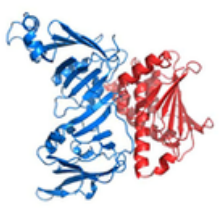

Figure 3 Hsp90 could interact with pUL42 protein $A$. The phylogenetic tree analysis between HSV-1 UL30 and other Herpesviridae virus DNA polymerase catalytic subunit. B. The phylogenetic tree analysis between HSV-1 UL42 and other Herpesviridae virus DNA polymerase processivity factor. $\mathrm{C}$. The cartoon schematic from protein docking stimulation between UL30 and Hsp90 $\beta$. D. The cartoon schematic from protein docking stimulation between UL42 and Hsp90 $\beta$.E.HFF cells were infected with HSV-1(MOI=20) and treated with Hsp90 inhibitor 17-AAG at 4h.p.i.And the co-immunoprecipitation was manipulated at $12 \mathrm{~h} . \mathrm{p} . \mathrm{i}$.

\section{Figure 3}

Caption found in figure. 

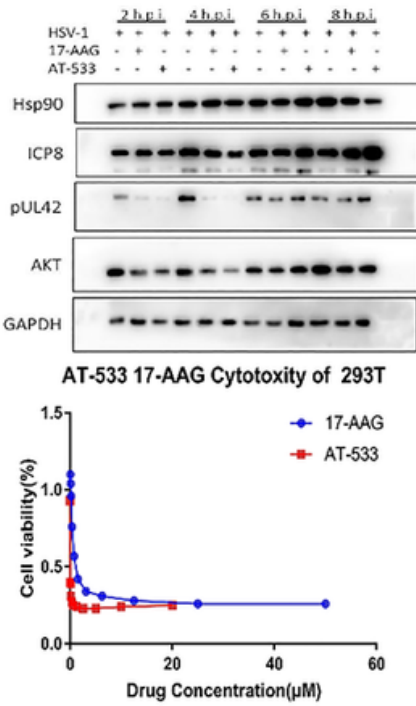

E

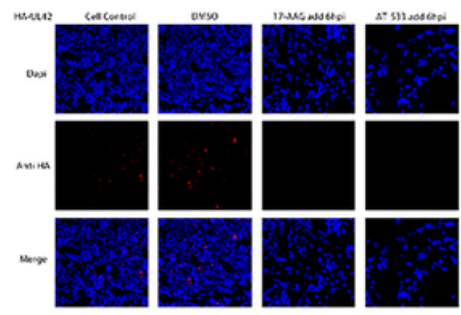

B

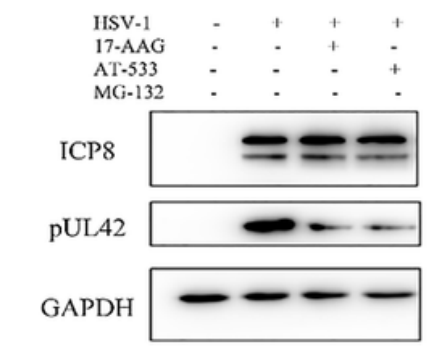

D
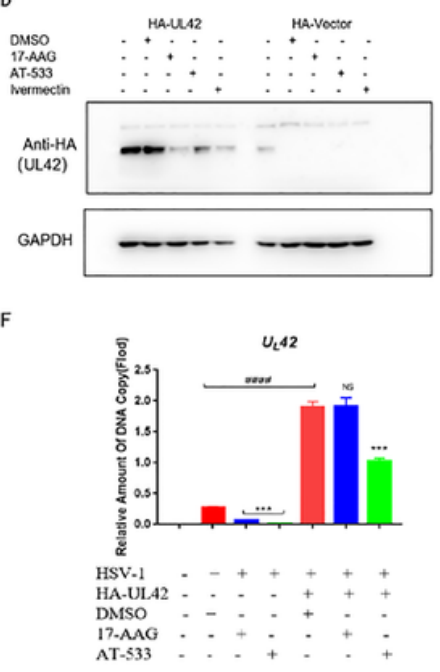

A

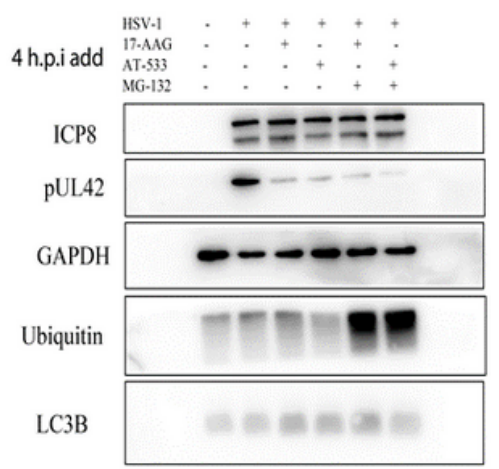

C

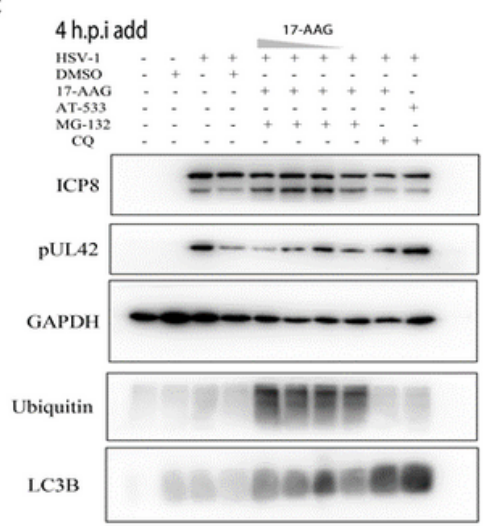

B
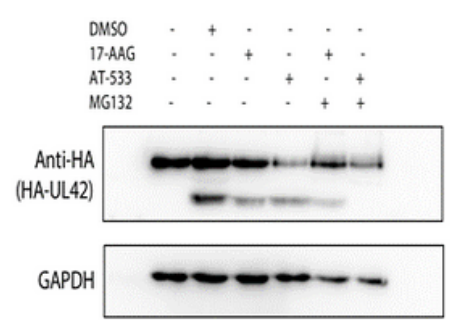

D

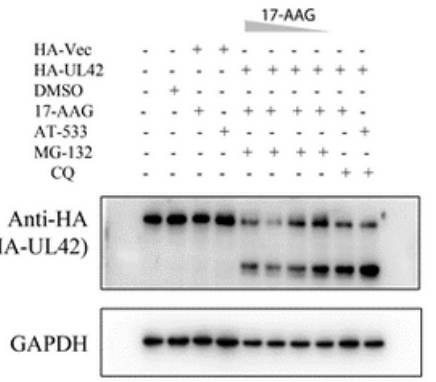

Figure $4 \mathrm{Hsp} 90$ inhibitors suppressed viral and plasmid pUL42 protein expression A. HFF cells were infected with HSV-1(MOI=20) and treated with Hsp90 inhibitors at different time points(2,4,6,8h.p.i). Western blotting was assayed to detect the replicationrelated viral proteins at 12 h.p.i. B.HFF cells were infected with $\mathrm{HSV}-1(\mathrm{MOI}=20)$ and treated with $\mathrm{Hsp} 90$ inhibitors at 4 h.p.i. Western blot was assayed to detect the replication-related viral proteins at $12 \mathrm{~h}$.p.i. C. Effects of AT-533 and 17-AAG of the viability for $48 \mathrm{~h}$ in HEK293T cells. D.HEK293T cells were transfected with HA-UL42 and HA-Vector plasmid refreshed with $2 \%$ FBS DMEM contained Hsp90 inhibitors at 6h.p.i and cell lysates were subjected to western bolt assay at 12h.p.i. E.HEK293T cells were transfected with HAUL42 plasmid refreshed with $2 \%$ FBS DMEM contained Hsp 90 inhibitors at 6 h.p.i and cell lysates were subjected to protein immunofluorescence assay at $12 \mathrm{~h}$.p.i. F.HEK293T cells were infected with HSV1(MOI=20) and Hsp90 inhibitors, and cell lysates were subjected to DNA copy number detection.
Figure 5 Hsp90 inhibitors induced the degradation of pUL42 via autophagy A.HFF cells were infected with HSV-1(MOI=20) and treated with Hsp90 inhibitors and proteasome inhibitor MG-132 $(10 \mu \mathrm{M})$ at 4h.p.i,and cell lysates were subjected to western blot assay to assess different viral protein. B. HEK293T cells were transfected with HA-UL42 plasmid and refreshed with $2 \%$ FBS DMEM contained Hsp90 inhibitors at $6 \mathrm{~h} . \mathrm{p} . \mathrm{i}$, and cell lysates were subjected to western blot. C.HFF cells were infected with HSV$1(\mathrm{MOI}=20)$ and treated with different concentrations Hsp90 inhibitors and proteasome inhibitor MG$132(10 \mu \mathrm{M})$, autophagy inhibitor $\mathrm{CQ}(50 \mu \mathrm{M})$, and cell lysates were subjected to western blot. D.HEK293T cells were transfected with HA-UL42 plasmid and treated with different concentrations Hsp90 inhibitors

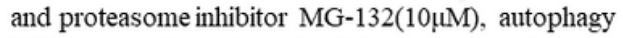
inhibitor CQ $(50 \mu \mathrm{M})$, and cell lysates were subjected to western blot. 
Figure 5

Caption found in figure.

A
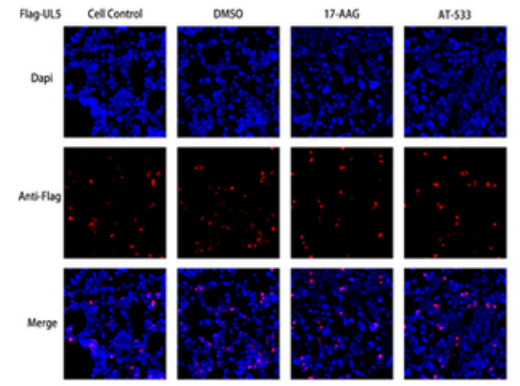

C
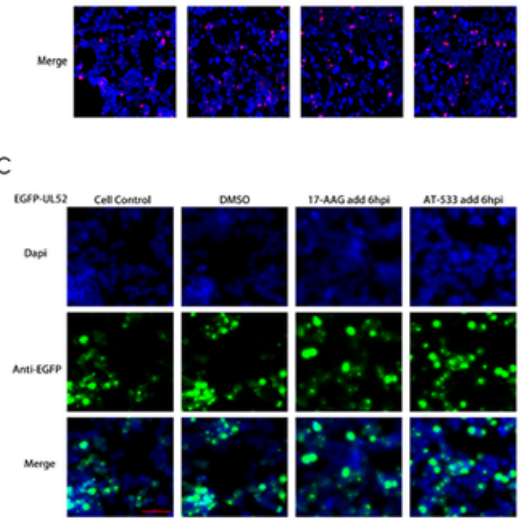

B

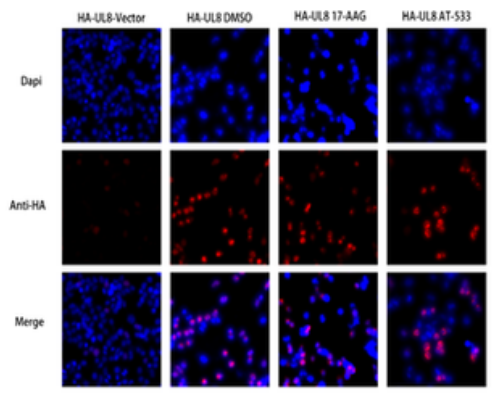

Figure 6 Hsp90 inhibitor couldn't suppress pUL5UL8-UL52 expression A.HEK293T cells were transfected with Flag-UL5 plasmid and refreshed with $2 \%$ FBS DMEM contained with Hsp90 inhibitors, and cell lysates were subjected to protein immunofluorescence assay. B.HEK293T cells were transfected with HA-UL8 plasmid and refreshed with $2 \%$ FBS DMEM contained with Hsp 90 inhibitors, and cell lysates were subjected to protein immunofluorescence assay. C.HEK293T cells were transfected with EGFP-UL52 plasmid and refreshed with $2 \%$ FBS DMEM contained with Hsp90 inhibitors, and cell lysates were subjected to protein immunofluorescence assay.

\section{Figure 6}

Caption found in figure. 


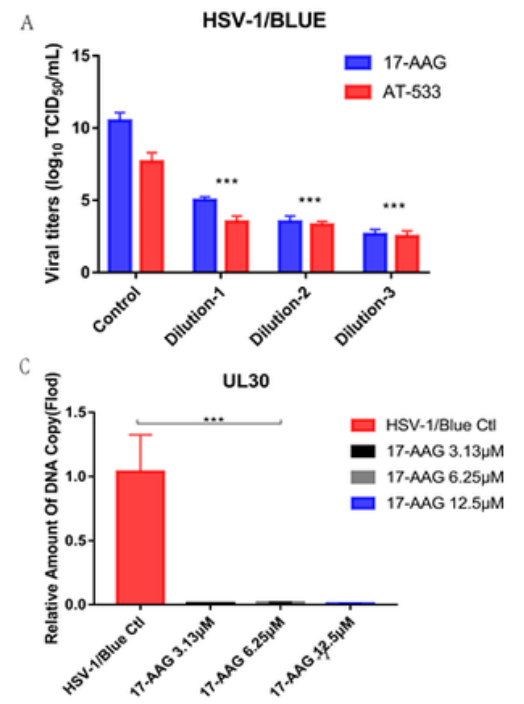

B

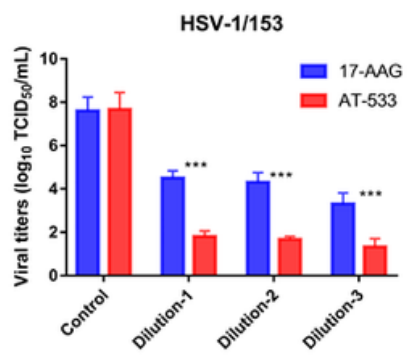

$\mathrm{D}$

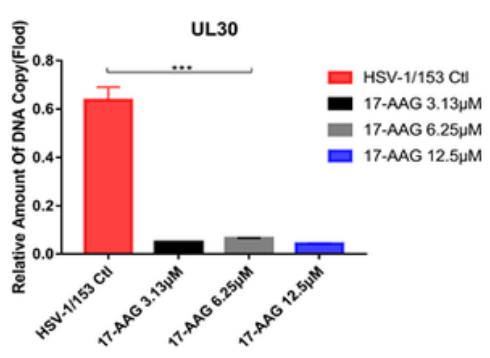

E

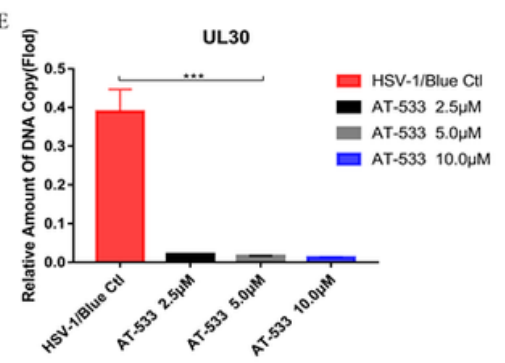

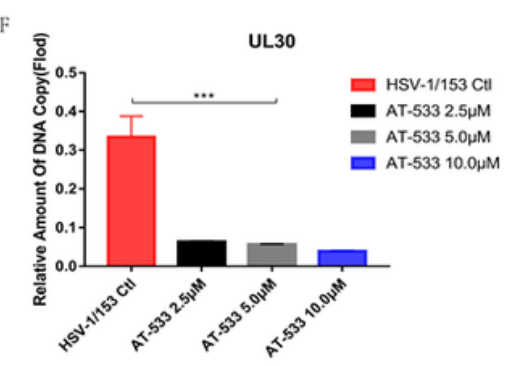

Figure 7 Hsp90 inhibitors reduced HSV-1/153 \& Blue virus titer and DNA replication A.HFF cells were infected with $\mathrm{HSV}-1 / \mathrm{Blue}(\mathrm{MOI}=1)$ and treated with $\mathrm{Hsp} 90$ inhibitors at 4 h.p.i, and at 12 h.p.i cell lysates were subjected to vero cells 96 wells-plate to asses viral titer. B.HFF cells were infected with HSV$1 / 153(\mathrm{MOI}=1)$ and treated with Hsp90 inhibitors at 4 h.p.i, and at $12 \mathrm{~h}$.p.i cell lysates were subjected to vero cells 96 wells-plate to asses viral titer. Dilution 1:17-

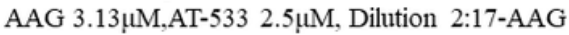
$6.25 \mu \mathrm{M}$ ，AT-533 5.0 $\mu \mathrm{M}$ ， Dilution 3:17-AAG $12.5 \mu \mathrm{M}$, AT-533 $10.0 \mu \mathrm{M}$. (C and D) HFF cells were infected with HSV-1/Blue (MOI=5) and treated with 17-AAG or AT-533 at 4 h.p.i,and cell lysates were subjected to viral DNA copy number detection at 12 h.p.i.(E and F) HFF cells were infected with HSV$1 / 153(\mathrm{MOI}=5)$ and treated with $17-\mathrm{AAG}$ or AT- 533 at 4 h.p.i,and cell lysates were subjected to viral DNA copy number detection at 12 h.p.i.

\section{Figure 7}

Caption found in figure.

\section{Supplementary Files}

This is a list of supplementary files associated with this preprint. Click to download.

- SupplementalTables.docx 